\title{
CHAMADOS A PARTICIPAR DO MISTÉRIO DE DEUS: A COMUNICAÇÃO DO AMOR NA RELAÇÃO ENTRE GRAÇA E CARISMA
}

\author{
Júnior Ribeiro da Silva* \\ "Qual é o desejo de Deus? \\ O desejo de Deus está no coração do homem? \\ Uma vez que ele fora criado por e para Deus. \\ Invocar-te ou louvar-te; conhecer-te ou invocar-te. \\ Mas quem te invocará sem te conhecer? \\ Pois fizeste-nos para ti, \\ e inquieto está o nosso coração, \\ enquanto não repousa em ti" \\ (S. Agostinho: Confissões, 1984, p. 15)
}

\begin{abstract}
RESUMO
O objetivo desse texto inclina-se numa perspectiva reflexiva em torno da forma e da estrutura que constituem o discurso sobre a relação entre Graça e Carisma, presente nos discursos pastorais. Faz-se necessário perceber que a qualidade da nossa teologia do Espírito deve ser intensamente abrangente, e não precária. O conjunto textual quer mostrar a importância da presença
\end{abstract}

\begin{abstract}
The aim of this paper leans on a reflexive perspective around the shape and structure that constitute the discourse on the relationship between grace and charisma, this pastoral discourses. It is necessary to realize that the quality of our theology of the Spirit must be thoroughly comprehensive, rather precarious. All textual want to show the importance
\end{abstract}

\footnotetext{
* Júnior Ribeiro da Silva: salesiano de Dom Bosco, licenciado em Filosofia pela Universidade Católica Dom Bosco (UCDB-MS), especialista em Educação Sexual pelo Centro Universitário Salesiano de São Paulo (UNISAL-SP), Bacharelando de Teologia pelo UNISAL, e pós-graduando em Bioética e Pastoral da Saúde no Centro Universitário São Camilo, São Paulo, e pesquisador do Centro Universitário Católico Salesiano "Auxilium" (UNISALESIANO - LINS, SP).
} 
do Espírito presente na vida da Igreja (por meio dos carismas) e do cristão (graça, dom gratuito de Deus), o qual é verdadeiramente sinal e a garantia da verdade da vida e da liberdade, testemunhada pela própria vida de Jesus, que perante a presença viva do Espírito, afirmou ser o caminho, a verdade e a vida.

Palavras-chave: Ser humano. Graça. Carisma. Igreja. Deus. Santidade. of this presence of the Spirit in the Church (through charisms) and Christian (grace gift of God), which is truly a sign and guarantee of the truth of life and freedom, as witnessed the very life of Jesus, who before the living presence of the Spirit, said to be the way, truth and life.

Keywords: Human. Grace. Charisma. Church. God. Holiness.

\section{INTRODUÇÃO}

Por meio dos textos extraídos das Sagradas Escrituras, do Catecismo da Igreja Católica, dos Documentos da Igreja, por meio de aulas desenvolvidas e ministradas na academia, áreas especificas de Trindade e de Pneumatologia, frente a alguns teólogos, os quais são os nossos principais interlocutores. Pretendo com esse trabalho desenvolver uma reflexão sobre a relação entre Graça e Carisma, pontuada por meio de leituras reflexivas, cujo assunto, é pontuado amplamente por atingir relevância intensa, sobretudo no que tange os elementos que constituem e configuram os nossos discursos pastorais.

Tomás de Aquino, com sua sábia atividade intelectual e reflexiva, em seus escritos afirmou nos discursos, que de Deus nada sabemos concretamente, a não ser pela via apofática, negação dos limites, pois falamos a partir da criação, das próprias criaturas; Deus é amor, bondade, compaixão, misericórdia... as quais são nossas vias de excelência. Envolto nessa dinâmica do mistério, vemos a necessidade de purificar nossos discursos, para falar e transmitir aquilo que recebemos 'Daquele' que tanto nos convida para estarmos em comunhão íntima do seu projeto de amor.

Somos pessoas a partir do momento que nos relacionamos com o outro. A pessoa humana ela não se constitui pessoa, quando não há uma qualidade de relação com o outro. A negação da pessoa é a violência; a qualidade da relação é o que nos introduz para sermos realmente pessoa. O que é mais importante é qualidade daquilo que a gente vive, e que vive com o outro; a pessoa é entendida como um ser de relação, não pela sua 
autonomia, a subsistência, mas o que importa é qualidade da relação como outro; isso pode-se dizer que se confirma com a pessoa divina, que é dom da reciprocidade, constituída pela relação, pela reciprocidade. Quando falamos de três pessoas, falamos de analogado, o amor do próximo é economicamente o amor do outro em Deus. A pessoa é pura inter-personalidade; a perfeição dos três é a unidade, se pode desenvolver uma teologia dos três a partir da personalidade, da gratuidade recíproca.

A reflexão em torno desse trabalho é concebida por uma lógica, que em primeira instância, evidência as riquezas dadas ao homem por Deus; e num segundo momento uma reflexão mais aprofundada sobre a graça e o carisma.

Todavia, o dom passa a ser o elemento decisivo do outro. O dom ao outro é o caminho da salvação, a nossa salvação não é simplesmente uma conquista pessoal, mas consiste na atitude pessoal em relação ao outro, dando-nos ao outro, assim realizamos a perfeição da nossa pessoa; o dar-se ao outro tem uma dimensão salvadora. Portanto, crê-se que a teologia se faz com percepções, e não apenas com conceitos, com conclusões.

A teologia, parte da fé objetiva, a Palavra de Deus, como tal está consignada na Tradição e na Sagrada Escritura. O papel teológico não se resume num mero ato especulativo sobre Deus, mas uma reflexão baseada na revelação, qual foram dadas por meio de experiências de autores sagrados, deixadas por escritos, constituídas, como formulações de experiências, e de testemunhos. Deus se revelou na história como um Deus apaixonado pela existência e salvação e bem-estar dos seres humanos; nós seres humanos experienciamos Deus em veiculação categorial historial. ${ }^{1}$

É preciso ter uma percepção à luz da fé, para assim estarmos profundamente abertos para a ação do Espírito, a morada da graça, do dom gratuito de Deus, cujo desejo maior é a nossa santificação. Para tanto, o papel primaz da teologia está na busca pela inteligibilidade da fé; está inteiramente subordinada à fé. Sua fonte é a fé, a qual consiste numa adesão pessoal a Deus, numa experiência pessoal da Realidade primeira, numa relação vivenciada com Deus. ${ }^{2}$

1 KESSLER, Hans. Jesus Cristo, caminho da vida. In: SCHNEIDER, Theodor (org.). Manual de Dogmática. v. 1. Petrópolis: Vozes, 2002, p. 55.

2 CATÃO, Francisco. Falar de Deus: Considerações sobre os fundamentos da reflexão cristã. São Paulo: Paulinas, 2001, p. 20. 


\section{O SER HUMANO CRIADO E SALVO PELA GRAÇA DE DEUS}

"Chamado à felicidade, mas ferido pelo pecado, o homem tem necessidade da salvação de Deus. O socorro divino lhe é dado, em Cristo, pela lei que o dirige e na graça que o sustenta". ${ }^{3}$

No relato da criação o ser humano, pois, é antes de tudo criatura de Deus, feito à imagem de Deus e salvo por graça de Deus. Seu ser e sua vida dependem a tal ponto de Deus, que o pecado, herdado dos primeiros pais, torna vãos, suspeitos e até mesmo ímpios todos os movimentos que pretenda fazer para realizar-se pessoalmente ou em sociedade. ${ }^{4}$ Além disso, um universo que é criação de Deus, à imagem do Filho no seio do Espírito Santo, é um universo abençoado, salvo e seguro. Cada criatura torna-se um sinal, um sacramento da bondade e da graça do Criador. A teologia da criação, em sua linguagem, confunde-se com as palavras e com o olhar do poeta e do místico: a criação é obra do amor de Deus. ${ }^{5}$

No querer e no desejo profundamente marcante de Deus, encontramos traços de Alguém que nos ama e nos quer amando-o, Deus nos chama à verdadeira vida, de participação da Comunhão, que Ele mesmo é, e isto por toda a eternidade. Essa relação de intimidade, constituída nesse querer de Deus, nesse amor pessoal com que nos ama, é o que finalmente dá sentido a tudo, o caracteriza como Deus e sustenta a plena realização de nós mesmos. Assim, a sua criatura é convidada ao mesmo fim, o próprio Deus.

Existe certa semelhança entre a união das pessoas divinas e a fraternidade que os homens devem estabelecer entre si, na verdade e no amor. $\mathrm{O}$ amor ao próximo é inseparável do amor de Deus ${ }^{6} \mathrm{O}$ homem foi criado para amar, para ser um dom para Deus e para o próximo. A pessoa humana tem necessidade de vida social. Esta não constitui para ela algo acrescentado, mas é uma exigência de sua natureza. Mediante o intercâmbio com os outros, a reciprocidade dos serviços e o diálogo com seus irmãos, o homem desenvolve as próprias virtualidades; responde assim à sua vocação. ${ }^{7}$

\footnotetext{
Catecismo da Igreja Católica. Edição Típica Vaticana. São Paulo: Loyola, 2000, nº 1949.

Cf. Francisco Catão, 2001, p. 10.

5 SUSIN, Luiz C. A criação de Deus. São Paulo: Paulinas; Valência, ESP: Siquem, 2003, p. 169.

6 Cf. Catecismo da Igreja Católica, 2000, n 1878.

7 Ibid., $n^{\circ} 1879$.
} 
A criatura inteligente, com efeito, pela sua operação, tende para semelhança divina, não somente para conservar-se no ser, nem apenas para multiplicar o seu ser, comunicando-se assim de algum modo, mas também para ter em si em ato o que, por natureza, tem em potência. $\mathrm{O}$ fim, portanto, da criatura intelectual, que é pela sua operação atingida, é conhecer em ato, pela sua inteligência, todas as coisas inteligíveis, para as quais está também em potência. É por essa maneira que ela se torna o mais possível semelhante de Deus. ${ }^{8}$

Impreterivelmente, a orientação para Deus é a dimensão mais íntima e radical de toda criatura. Todavia, o homem, criado à imagem de Deus, como ser pessoal, é chamado a assumir e a viver consciente e livremente a relação com Deus. É chamado a deliberar e a se decidir pela aceitação do Deus criador-salvador (tendo a possibilidade real de se fechar ao apelo).

Contudo, a aceitação bíblica do valor da relação homem-Deus não deve ser mal compreendida, pois a abertura ao Deus-Ágape implica sempre compromisso com a justiça e com o amor-serviço, solidário. A maior aceitação do Deus-Ágape, maior compromisso com o ser humano e vice-versa. Para a fé cristã, o homem é pessoa acima de tudo porque é capaz de responder a Deus, de dialogar com Ele e de aceitar a sua proposta. Entre a pessoa humana e Deus existe uma relação única, própria, exclusiva e irrepetível. ${ }^{9}$

Após uma rápida descrição da profunda interligação de amor e bondade que há entre o Criador e sua criatura, deteremos agora em aprofundar a relação entre carisma e graça, com a intenção de aprofundar a qualidade do nosso discurso sobre a nossa teologia do Espírito.

\section{GRAÇA}

"Se conhecesses o dom de Deus e quem é que te diz:

'Dá-me de beber', tu é que lhes pedirias e ele

te daria água viva!"(Jo 4,10$)$

8 AQUINO, Tomás de. Santo. Compêndio de Teologia. Coleção Teologia, vol. 6. $2^{\mathrm{a}}$ edição. Porto Alegre: Edipucrs, 1996, p. 114.

9 KASPER, Walter. El Dios de Jesucristo. Salamanca: Sígueme, 1986, pp. 89-142. 
No Antigo Testamento este conceito teológico se identifica com a misericórdia, com a justiça e com a fidelidade de Deus; está sempre presente no contexto histórico salvífico da Aliança, fluido nas obras de misericórdia de Deus para com seu povo. Já no Novo Testamento, a acepção básica do termo, graça (haris). Descreve a relação entre duas pessoas em termos de bondade, condescendência, gratuidade, gratidão e alegria. ${ }^{10}$

Ora, no Catecismo, graça é definida como favor gratuito que Deus nos oferece para responder ao seu chamado de sermos filhos de Deus. A graça é uma participação profunda na vida de Deus. Abrange toda a inclinação de Deus para a Criação, desde a graciosa predestinação, passando pela humanização e pelo morar na alma dos agraciados, até a beatífica contemplação de Deus. ${ }^{11}$ Assim, somos introduzidos de forma plena dentro do Mistério Trinitário.

A graça é antes de tudo e principalmente o dom do Espírito que nos justifica e nos santifica. Mas a graça compreende igualmente os dons que o Espírito nos concede, para nos associar à sua obra, para nos tornar capazes de colaborar com a salvação dos outros e com o crescimento do corpo de Cristo, a Igreja. ${ }^{12}$

Graça não é qualidade, quer criada quer não-criada, mas designa a relação entre Deus e ser humano. Esta, naturalmente não é relação entre iguais, de modo que graça é formulada mais precisamente como conduta de Deus para com os seres humanos, a qual naturalmente "não deixa de ter efeito real sobre a criatura, tornando-se inerente ao ser humano. Nesse sentido, mas permanecendo 'princípio exterior' no mais, ou seja, aquele 'amor especial' no qual Deus se doa a si próprio ao ser humano e o qual é idêntico à predestinação divina. [...] Graça

\footnotetext{
10 Haja vista, que na história da teologia, o termo, graça passou por uma série de variações, sobretudo por ser um dos temas essências da fé. Tal como ela se expressava no Novo Testamento (cuja redução farisaica da graça puramente ética (observância da Lei;); a espiritualização da graça (atuante só na alma e não no corpo). Já nos Séc. II e III a Teologia enfrentou o a dificuldade com o gnosticismo (o que salva seria o conhecimento, e não a graça). EICHER, Peter. Dicionário de Conceitos Fundamentais de Teologia. Tradução: João Rezende Costa. São Paulo: Paulus, 1993, p. 253.

11 SHENEIDER, Theodor. Manual de Dogmática. VI. II. $3^{\text {a }}$ edição. Petrópolis, RJ: Vozes, 2008, p. 28.

12 Cf. Catecismo da Igreja Católica, 2000, nº 2003.
} 
é atuação divina junto à natureza humana, a qual precisa ser preparada para receber a graça. ${ }^{13}$

Contudo, a palavra graça, pode ser entendida como efeito de Deus ou dom de Deus, na tradição mais antiga se fala de efeito, da graça habitual. Disposição permanente para viver e agir conforme o chamado divino. ${ }^{14} \mathrm{~A}$ graça como efeito de Deus, pela ação de Deus, somos agraciados, Maria foi agraciada. "Alegra-te ò cheia de graça o Senhor é contigo [...] Encontraste graça junto de Deus" (Lc 1,28-30).

Essa graça, dom de Deus, ela só é efetiva na medida em que for recebida, não se estabelece de forma semelhante a um dinheiro que é colocado numa conta bancaria; só é ação em mim, a partir do momento que é recebido, que há uma abertura, onde haja uma relação recíproca, de acolhimento dessa graça dada a cada um.

A ação santificadora é ação divina, mas nasce em nós e por nós. Dá-se em primeiro lugar, em nosso intimo, é mudança do coração, do espírito, metanóia, conversão contínua, na fonte de todo agir cristão humano, pois a vocação fundamental de todo ser humano é a vocação à santidade. Dando-se no nosso intimo, a ação divina santificadora do Espírito não se dá sem nós, dá-se por nós. A correspondência pessoal e livre á ação de Deus atuante em nós integra a ação santificadora do Espírito, que não nos santifica de fora, mas nos transforma interiormente, com o sim de nossa liberdade, tornando-nos santos, filhos de Deus. ${ }^{15}$

A palavra graça pode nos remeter a um gesto profundamente gratuito dado exclusivamente por Deus, independente do nosso ato de querer ou de receber. Tomás afirma que o ser humano em si mesmo, "nada pode fazer para o seu agraciamento, antes, ele sempre já está abarcado pela graça em todos os sentidos". 16

Ela é um evento, uma realidade que não depende de nós, opera no acolhimento, no espírito livre, na liberdade; essa graça é o Espírito Santo, que é um dom de Deus, dada de forma gratuita, e quando é

\footnotetext{
13 Manual de Dogmática, 2008, pp. 28-29.

14 Cf. Catecismo da Igreja Católica, 2000, n² 2000.

15 Cf. Francisco Catão, 2001, p. 122.

16 Cf. Manual de Dogmática, 2008, p. 30.
} 
recebido, nos possuímos o Espírito, nos possuímos a graças, assim, nos tornamos santos.

Todos que no Espírito Santo experimentam a graciosa dedicação de Deus e professam que, sem qualquer direito próprio, por pura graça, foram justificados perante Deus em Jesus Cristo, resgatados da escravidão e acolhidos como filhos e filhas do Pai, o Espírito reúne na comunhão da graça que é a Comunidade-Igreja, para cuja edificação ele concede seus dons e graças. ${ }^{17}$

Quanto falo Espírito, deve entendê-lo como dom gratuito de Deus; no entanto, só será real a partir do momento que houver uma acolhida. Para Tomás, os seres humanos estão destinados à consumação em Deus por graça e em graça. ${ }^{18}$ As faculdades do homem o tornam capaz de conhecer a existência de Deus. Mas, para que o homem possa entrar em sua intimidade, Deus quis revelar-se ao homem e dar-lhe a graça de poder acolher esta revelação na fé. ${ }^{19}$

Graça é a criadora chegada do eterno amor de Deus no centro do eu do ser humano. Dentro da limitação em sua natureza, o ser humano é arrancado e elevado para a comunhão de vida com Deus, ao mesmo tempo em que é equipado com as capacidades que Iho tornam possíveis e até difíceis e óbvio: da graça fluem fé, esperança e amor (O.H. Pesch/ A. Peters, Einführung, 89). ${ }^{20}$

Ao notar em Jesus de Nazaré, o grande mensageiro do Senhorio de Deus, ungido pelo Espírito, enviado para proclamar um ano da graça do Senhor (Lc 4,19), percebemos que Nele se encontra o verdadeiro testemunho da Santidade, que fora do alcance de leis e de normas, se abre definitivamente à ação de Deus. É por isso que com razão, o Jesus proclamador passou do senhorio a ser o Cristo proclamador, isso dá a ele a ser chamado de forma pessoal do senhorio de Deus, graça de Deus em pessoa. ${ }^{21}$ Desde o inicio a graça de Deus estava com ele (Lc 2,40); que ele encontrou graça junto

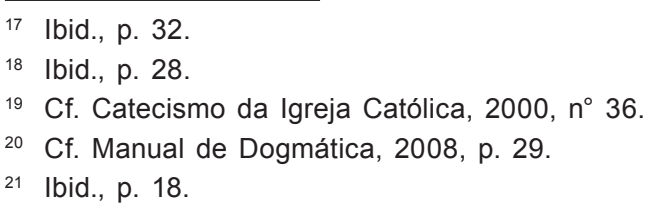

108 ReVISta de Cultura TeOlógica - v. 19 - N. 73 - JAN/MAR 2011 
de Deus e às pessoas (Lc 2,52); que ele pronunciou palavras de graça (Lc 4,22), sim ele é a própria palavra de graça de Deus encarnada (Jo 1,14).

Ora, a Graça é germe da santidade; falar da graça como dom, é falar daquilo que vem e que é dado somente pela própria ação do Espírito; a ação do espírito nos leva a fazer uma profunda experiência do amor, pois estamos diante de uma ação santificadora, transformadora, que se dá em nosso íntimo, cujas mudanças se dão no coração. A vida no Espírito, que brilha em Cristo como no sol e reflete-se em Maria como na lua, chega até nós, em alternâncias de dias e noites, até que sejamos todos reunidos no dia eterno de Deus. ${ }^{22}$

\subsection{A conexão entre as categorias: relação e homem}

Evidenciar uma reflexão sobre esses dois termos possibilita aplacá-los numa junção profundamente importante, dentro do cenário atual, sobretudo no que tange as práticas pastorais, exercidas constantemente em nossos ambientes educativos e religiosos.

A relação dialogal para Martin Buber só se constrói por meio da confiança, reciprocidade, comprometimento e, principalmente, do acolhimento e da abertura, duas categorias que não podem jamais se ausentar desse discurso. Pois, são características que marcam toda a relação; é um encontro, ação própria de um diálogo autêntico a ser estabelecido entre o Criador e a sua Criatura.

Marcio Vidal afirma que a presença da intersubejtividade e da alteridade, dá ao homem a capacidade de abertura, tornando-o, uma pessoa de estrutura dialogal; essa caracterização permite dizer que é uma antropologia do diálogo, em que o Eu constitui-se na referência a um Tu. ${ }^{23}$ Contudo, o Eu e o Tu se estrutura numa originalidade genuína de encontro interpessoal, e, somente após a relação face-a-face, é que acontece a verdadeira experiência de encontro.

Todo diálogo que acontece é sempre dirigido, governado e conduzido por um ser dotado de capacidade para alguém; o diálogo como atividade,

22 Cf. Francisco Catão, 2001, p. 189.

23 VIDAL, Marcelo. Antropología e Teológica y Mora. Fundamentación de la moral según Santo Tomás: Pentecostes 12, 1975, p. 146. 
ou como um conjunto de ações e de modalidades, é um evento no qual possibilita o homem fazer-se homem. ${ }^{24} \mathrm{~A}$ autonomia do ser humano se eleva em função da sua habitação no mundo que se estende para além do observador que 'no' mundo se encontra, e que como tal é autônomo [...] o homem é propriamente o ser-no-mundo e como tal é capaz de diferenciar-se dele, atuando em prol de suas transformações. ${ }^{25}$

O aspecto mais sublime da dignidade humana está na vocação do homem à comunhão com Deus. Este convite que Deus dirige ao homem, de dialogar com ele, começa com a existência humana. Pois se o homem existe, é porque Deus o criou por amor e, por amor, não cessa de dar-lhe o ser, e o homem só vive plenamente, segundo a verdade, se reconhecer livremente este amor e se entregar ao seu Criador. ${ }^{26}$

\section{CARISMA}

Deus não tem outra razão para criar a não ser seu amor e sua bondade "Aberta à mão pela chave do amor, as criaturas surgiram". ${ }^{27}$

Falar de carisma, na concepção Trinitária de São Paulo, é graça que na sua multiforme diversidade, ou vem do Pai como modos de ação, ou vem do Filho como ministérios, ou vem do Espírito como dons.

Há diversidade de dons, mas o Espírito é o mesmo; diversidade de ministérios, mas o Senhor é o mesmo; diversos modos de ação, mas é o mesmo Deus que realiza tudo em todos. Cada um recebe o dom de manifestar o Espírito para a utilidade de todos. A um, o Espírito dá a mensagem de sabedoria, a outro, a palavra de ciência segundo o mesmo Espírito; a outro, o mesmo Espírito dá a fé; a outro ainda, o único e mesmo Espírito concede dons de curas; a outro, o poder de fazer milagres; a outro, a profecia; a outro, o discernimento dos espíritos; a outro, o dom

24 Dicionário de Filosofia. São Paulo: Martins Fontes, 2007, p. 324.

25 SANTIAGO, Maria Betânia do Nascimento. Diálogo e Educação: O pensamento pedagógico em Martin Buber. Tese de Doutorado - Universidade Federal de Pernambuco. CE. Educação, Cecife, 2008. Santiago, 2008, p. 54.

26 Cf. Catecismo da Igreja Católica, 2000, n 28.

27 Ibid., $\mathrm{n}^{\circ}$ 293. Sto. Tomás de Aquino, In II Sent., prol.

110 ReVISTA de CULtURA TEOLÓGICA - V. 19 - N. 73 - JAN/MAR 2011 
de falar em línguas, a outro ainda, o dom de as interpretar. Mas é o único e mesmo Espírito que isso tudo realiza, distribuindo a cada um os seus dons, conforme Ihe apraz. (1Cor 12,4-11).

Nota-se que o carisma deve ser acolhido com reconhecimentos por aqueles que os recebe, mas também por todos os membros da Igreja, ${ }^{28}$ pois estes estão repletos de maravilhas que operam fortemente na ação apostólica e em todo o Corpo Santo de Cristo. Ora, os carismas são graças do próprio Espírito Santo, que operam profundamente de forma ordenada à edificação de toda Igreja, cujo fim, se configura de forma esplendorosa para o bem comum dos homens e às diversas necessidades do mundo.

Desde a origem, esta Igreja una se apresenta com uma grande diversidade, que provém ao mesmo tempo da variedade de dons de Deus e da multiplicidade das pessoas que o recebem. Na unidade do povo de Deus se congregam as diversidades dos povos e das culturas. Entre os membros da Igreja existe uma diversidade de dons, de encargos, de condições e de modo de vida. ${ }^{29}$

Aquele que tem carisma ${ }^{30}$ é o que tem plenas condições e capacidade de saber conectar-se com os outros, é um dom natural ou divino que não pode ser suprimido com o estudo e o saber. Todavia, é um conceito que implica dom ou favor divino em prol de uma determinada comunidade, bem como, capacidade de comunicar-se e de atrair outras pessoas.

Dizer que o carisma está inserido numa dimensão profundamente teológica e eclesial dá-nos a capacidade de afirmar que se trata de uma experiência estritamente pessoal, fora do alcance de qualquer principio normativo ou legalista, forjado só e exclusivamente numa íntima relação de proximidade com Deus, de auto-comunicação, primeiro nessa instância dialogal e depois com a comunidade.

Na sua raiz (háris), carisma significa graça. O carisma é uma graça especial e extraordinária ou uma graça simples e comum, pela qual o Espírito Santo torna a pessoa apta e pronta para edificar a Igreja, isto é, contribuir para a sua renovação e incremento. O Espírito quando escolhe alguém para agraciá-lo com seus carismas é para o bem de todos. Não há dom (graça) do alto, natural ou sobrenatural, eminente ou ordinário, somente para si. ${ }^{31}$

\footnotetext{
28 Ibid., $n^{\circ} 799$.

29 Ibid., $\mathrm{n}^{\circ} 814$.

30 JOSÉ, J. Tamayo. Novo Dicionário de Teologia. São Paulo: Paulus, 2009, p. 64.

31 LIMA, Marcos de. Inculturação do carisma? São Paulo: Loyolas, 2001, p. 87.
} 
Ao tratar a questão sobre a renovação carismática, o grande Teólogo Yves Congar afirma que, com exceção de 1Pd 4,10, o termo charisma só se apresenta nos textos de São Paulo 16 vezes, cujos usos são bem constantes, mesmo numa aplicação particular (2Cor 1,9): depende sempre da graça, charis. As palavras gregas em "-ma" (como em charis-ma) significam o resultado obtido por uma ação. No entanto, na sua percepção, o termo deve ser apresentado em relação com charis, graça. Antes de discorrer sobre o assunto, faz-nos importante evidenciar alguns traços que se apresenta na nota de rodapé da obra do Pe. Congar. ${ }^{32}$

\subsection{Carisma em função da graça}

Trabalhai para a vossa salvação com temor e tremor, pois é Deus quem, segundo a sua vontade, realiza em vós o querer e o fazer (FI 2,12-13).

A Graça é o que define o carisma como dom gratuito do Espírito Santo, destinado à edificação. Já o documento de Malines (In Lumen Vitae, 1947) afirma também: "Entendemos aqui por 'carisma' um dom interior, uma aptidão liberada pelo Espírito, revestida de força por ele e colocada a serviço da edificação do Corpo de Cristo. Todo cristão possui um ou mais carismas, em vista do ordenamento e dos ministérios da Igreja". Por fim, o Espírito Santo, que é dado a toda a Igreja, se faz visível e tangível através de diversos ministérios.

Mediante uma ampla visão do papel do Espírito em nossa vida, a vida no Espírito, como diz o Catecismo da Igreja Católica, é indispensável para compreendermos o sentido da renovação no Espírito, estritamente importante para a vida da Igreja hoje. Evita as dificuldades insolúveis do que se denominaram os movimentos pentecostais ou carismáticos, que tendem a se reclamar da vida no Espírito com base numa pretendida ação específica do Espírito, como que paralela à do Verbo, ao exaltar a experiência do Espírito como algo de especial, na raiz dos dons manifestos do Espírito, que são os carismas.

Na perspectiva de Yves Congar, três textos bíblicos norteiam a relação que há ao conceber carisma como graça, dons: Dou incessantemente graças

${ }^{32}$ CONGAR, Yves. Creio no Espírito santo 2. "Ele é o Senhor e dá a vida". Tradução: Euclides Martins Balacin. São Paulo: Paulinas, 2005, p. 214, Considerações obtidas na Nota de rodapé da obra: $n^{\circ} 2$.

112 ReVIsta de Cultura TeOlógica - v. 19 - N. 73 - JAN/MAR 2011 
a Deus a vosso respeito, em vista da graça de Deus que vos foi dada em Cristo Jesus. Pois fostes nele cumulados de todas as riquezas, todas as da palavra e todas as do conhecimento. Na verdade, o testemunho de Cristo tornou-se firme em vós, a tal ponto que nenhum dom vos falte, a vós que esperais a Revelação de nosso Senhor Jesus Cristo. (1Cor 1,4-7). Quisera que todos os homens fossem como sou; mas cada um recebe de Deus seu dom particular; um deste modo; outro daquele modo (1Cor 7,7). Há diversidade de dons, mas o Espírito é o mesmo; diversidade de ministérios, mas o Senhor é o mesmo; diversos modos de ação, mas é o mesmo Deus que realiza tudo em todos. Cada um recebe o dom de manifestar o Espírito para a utilidade de todos. A um, o Espírito dá a mensagem de sabedoria, a outro, a palavra de ciência segundo o mesmo Espírito; a outro, o mesmo Espírito dá a fé; a outro ainda, o único e mesmo Espírito concede dons de curas; a outro, o poder de fazer milagres; a outro, a profecia; a outro, o discernimento dos espíritos; a outro, o dom de falar em línguas, a outro ainda, o dom de as interpretar. Mas é o único e mesmo Espírito que isso tudo realiza, distribuindo a cada um os seus dons, conforme Ihe apraz. (1Cor 12, 4-11).

O homem, impelido pela Graça, na sua aspiração não cessa de afastar dos seus olhos o impulso contínuo de conhecer e de aproximar do amor de Deus. Tomás insiste nesse participar de Deus: "A graça é uma certa semeIhança com Deus de que o homem participa" (III, 2, 10 ad 1); "O primeiro efeito da graça é conferir um ser de alguma forma divino" (III, 2 d. 26, 155); "Pela graça santificante, toda a Trindade passa a morar na alma" $(I, 43,5) .{ }^{33}$ Como São Pedro (2Pd 1,4), participantes da própria vida íntima de Deus. $\mathrm{E}$ isto, diz Tomás, é a graça. Pois de sua plenitude todos nós recebemos graça por graça. (Jo 1,16).

Contudo, pode-se dizer que o carisma é uma forma evangélica de viver, é um dom suscitado pelo próprio Espírito; "Realmente, desejo muito ver-vos, para vos comunicar algum dom espiritual, que vos possa confirmar. $(\mathrm{Rm} 1,11)$. Assim, essa forma a Igreja reconhece-a como caminho seguro e apropriado para realizar e vivenciar o seguimento de Cristo Jesus. É um dom, e, portanto é dado de forma gratuita. Devem à graça ${ }^{34}$ de Deus, a qual visa à realização da salvação, e que eles são chamados a colocar a serviço da construção do Corpo de Cristo. Todavia, o Espírito não se esgota jamais em nenhuma de suas manifestações. ${ }^{35}$

\footnotetext{
33 NICOLAS. Marie Joseph. Suma Teológica de Tomás de Aquino. São Pulo: Loyola, 2001.

34 Cf. Yves Congar, vol. 2, p. 214.

35 Cf. Francisco Catão, pp. 111-112.
} 


\section{CONCLUSÃO}

Antes de se revelar ao homem em palavras de verdade, Deus se the revela pela linguagem universal da criação, obra de sua Palavra, de sua sabedoria: a ordem e a harmonia do cosmo - que tanto a criança como o cientista descobrem -, "A grandeza e a beleza das criaturas levam, por analogias, à contemplação de seu autor" (Sb 13,5), pois foi à própria fonte da beleza que as criou (Sb 13,3). ${ }^{36}$ Ora, falar de graça é falar sobre o principio de vida e ação do cristão, pois o cristão não é chamado a ater-se a lei, mas a graça. Graça é o amor de Deus, é originária e essencialmente uma realidade em Deus. A própria preparação do homem para acolher a graça é já uma obra da graça.

A vida no espírito implica fortemente uma intensa abertura e acolhimento, atitude própria do agir humano, que se torna efetiva somente por meio de uma resposta pessoal, ao qual se deixa guiar e conduzir pelos ensinamentos do amor de Deus. Karl Rahner afirma que o lugar originário onde fazemos a experiência da condição de criatura não é a cadeia dos fenômenos ocorrendo em temporalidade vazia, mas a experiência transcendental, onde o sujeito experimenta a si e seu próprio tempo, como sendo portados pelo fundamento incompreensível. ${ }^{37}$ Local onde se constrói a autocomunicação divina e a permanência no mistério. Em que Deus pode se comunicar a sua própria realidade a uma realidade não-divina, sem que deixe de ser a realidade infinita e o mistério absoluto e sem que o homem deixe de ser o ente finito e distinto de Deus que é. ${ }^{38}$

Lembramo-nos de que Tomás comparava o ato de ser das criaturas à luz e ao fogo: um ferro em brasa tem calor porque participa do fogo, que "é calor"; um objeto iluminado "tem luz" por participar do brilho que emana de uma fonte luminosa. Ora, quando Tomás fala da graça, vale-se exatamente das mesmas comparações. O próprio conceito de participação, utilizado neste sentido, encontra-o em textos do Novo Testamento, por exemplo, em $\mathrm{Hb}$ 3,14: "somos participantes de Cristo". 39

Falar sobre graça é falar da presença de Deus, do mesmo espírito que conduziu Jesus, comunicada por meio da sua presença, do seu testemunho,

36 Cf. Catecismo da Igreja Católica, 2000, $\mathrm{n}^{\circ} 2500$.

37 RAHNER, Karl. Curso Fundamental da Fé: Introdução ao Conceito de Cristianismo. Teologia Sistemática. São Paulo: Paulinas, 1989, p. 101.

38 Ibid., p. 149.

39 http://www.hottopos.com/mp3/sentom.htm\#agra. 
da sua identidade, da sua relação íntima, da sua vida íntima em e com Deus. Por meio da nossa liberdade e pela nossa adesão livre e pessoal, consolidado pelo nosso acolhimento da sua palavra, é que somos convidados a sermos portadores desse amor de Deus, no tempo e na história, convidados, por meio do nosso consentimento livre, a sermos pessoas cheias da ação do Espírito.

Ora, o carisma é dado em função da graça, da santidade pessoal dos membros, e da Igreja. A igreja é comunhão de graça, é o local onde os homens são chamados a fazer-se presente na história da salvação. A obra de Deus está situada na santidade. A ação do espírito não pode jamais conhecer fronteiras; a pessoa humana é digna porque Jesus assumiu a humanidade - toda humanidade está enriquecida pelo espírito de Jesus.

Contudo, o carisma é dado em função da graça para a comunidade em primeiro lugar, para os outros, e depois para as pessoas como forma e meio de conversão, como abertura à ação da graça, e como forma de demonstração da própria graça recebida e infundida por meio de milagres e outras ações do espírito. É o carisma que fortalece, que liga, e que intensifica as relações, ao passo que aí, encontra-se profundamente carregado de uma identidade, de uma expressão do amor de Deus para seu povo, que tanto ama e que deseja fazer dele participante do seu projeto íntimo de amor

A relação do homem se estabelece pela graça, o dom através do qual participa da vida divina, da vida de Deus, e somente depois, é que por meio dos carismas, que são conferidos é que ocorre a irradiação da graça, do perfume de Deus. Enfim, os carismas são sinais que legitimam e homologam a comunidade. Incumbe ao ministério hierárquico o dever de examinar e cultivar os carismas de acordo com a sua identidade original para a qual foi confiada ao povo de Deus. Tanto o Filho como o Espírito vêm historicamente aos humanos, chamados a recebê-los em suas vidas. ${ }^{40}$

\section{BIBLIOGRAFIA}

AGOSTINHO, Santo. Confissões. (Trad.) Maria Luiza Jardim Amantes. São Paulo: Paulus, 1984.

AQUINO, Tomás de. Santo. Compêndio de Teologia. Coleção Teologia, vol. 6, $2^{\mathrm{a}}$ edição. Porto Alegre: Edipucrs, 1996.

40 Cf. Francisco Catão, 2001, p. 113. 
Bíblia de Jerusalém. Nova edição, revisada e ampliada. (orgs.). Gorgulho, G. da S.; Storniolo, I.; Anderson, A. F. São Paulo: Paulus, 2002.

CATÃO, Francisco. Falar de Deus: Considerações sobre os fundamentos da reflexão cristã. São Paulo: Paulinas, 2001.

CATECISMO DA IGREJA CATÓLICA. Edição Típica Vaticana. São Paulo: Loyola, 2000. CONGAR, Yves. Creio no Espírito santo 2. "Ele é o Senhor e dá a vida". Tradução: Euclides Martins Balacin. São Paulo: Paulinas, 2005.

Dicionário de Filosofia. São Paulo: Martins Fontes, 2007.

EICHER, Peter. Dicionário de Conceitos Fundamentais de Teologia. Tradução: João Rezende Costa. São Paulo: Paulus, 1993.

http://www.hottopos.com/mp3/sentom.htm\#agra.

JOSÉ, J. Tamayo. Novo Dicionário de Teologia. São Paulo: Paulus, 2009.

KASPER, Walter. El Dios de Jesucristo. Salamanca: Sígueme, 1986.

KESSLER, Hans. Jesus Cristo, caminho da vida. In: SCHNEIDER, Theodor (org.). Manual de Dogmática, vol. 1. Petrópolis: Vozes, 2002.

LIMA, Marcos de. Inculturação do carisma? São Paulo: Loyola, 2001.

NICOLAS. Marie Joseph. Suma Teológica de Tomás de Aquino. São Paulo: Loyola, 2001.

RAHNER, Karl. Curso Fundamental da Fé: Introdução ao Conceito de Cristianismo. Teologia Sistemática. São Paulo: Paulinas, 1989.

SANTIAGO, Maria Betânia do Nascimento. Diálogo e Educação: O pensamento pedagógico em Martin Buber. Tese de Doutorado - Universidade Federal de Pernambuco. CE. Educação, Recife, 2008.

SHENEIDER, Theodor. Manual de Dogmática, Vol. II, $3^{a}$ edição. Petrópolis, RJ: Vozes, 2008.

SUSIN, Luiz C. A criação de Deus. São Paulo: Paulinas; Valência, ESP: Siquem, 2003.

VIDAL, Marcelo. Antropología e Teológica y Moral. Fundamentación de la moral según Santo Tomás: Pentecostes 12, 1975.

ZUBEN, N. Aquiles von. Martin Buber: cumplicidade e diálogo. Bauru, São Paulo: EDUSC, 2003.

116 ReVISta de Cultura TEOLÓgIcA - v. 19 - N. 73 - JAN/MAR 2011 